\title{
Protective ability of lamellar coatings in chemically and biologically active media
}

\author{
A.A. Kalinina, ${ }^{1 *}$ R.V. Galkin, ${ }^{2}$ V.I. Chumakov ${ }^{2}$ and V.I. Naumov ${ }^{1}$ \\ ${ }^{1}$ Nizhny Novgorod State Technical University n.a. R.E. Alekseev, Minin St., 24, 603950 \\ Nizhny Novgorod, Russian Federation \\ ${ }^{2}$ Chimsintez Co., Chimsintez, Nauka street, 606000 Dzerzhinsk, Russian Federation \\ *E-mail: 777aleksa777_87@mail.ru
}

\begin{abstract}
The paper compares the protective ability of lamellar coatings with various filler metals (zinc, aluminum and zinc-aluminum lamellas, as well as lamellas: metal powder combinations), binders (titanium oxide, epoxy and Teflon) and various structures (single-layer and two-layer coatings with various kinds of filler metals and binders). The expediency of using protective lamellae for protection in biologically aggressive environments is shown. It is shown that the amount of electrochemically active zinc added to lamellar coatings increases the protective ability of coatings by the same amount. When a fraction of zinc is replaced by a small amount of aluminum (3-7\%), the protective mechanism changes dramatically from $100 \%$ sacrificial mechanism to the prevailing barrier protection $\left(\gamma_{\mathrm{bar}} \approx 70 \%\right)$; the reasons for such a sharp change in the mechanisms of action and the reasons for the increase in the protective ability of such coatings are revealed in exhaustive detail and substantiated. It is shown that in the two-layer coatings under study, the contribution of the barrier mechanism is $8-16 \%$ greater than in singlelayer coatings due to the misalignment of the pore network in the first and second layers, as a result of which the interface between these layers plays the role of a "locking" layer.
\end{abstract}

Keywords: zinc-lamellar coatings, electrochemical and microbiological corrosion, bacteria, biofilms, hydrogen peroxide, ammonia, contributions of sacrificial and barrier protection, polarization plots.

Received: October 30, 2019. Published: April 16, 2020

doi: $\underline{10.17675 / 2305-6894-2020-9-2-8}$

\section{Introduction}

The destruction of metals due to chemical or electrochemical interaction with the environment causes enormous damage to the economies of developed countries that is estimated at tens to hundreds of billion dollars depending on the size of the industry and transport arteries.

Protection of metal against corrosion gives a huge economic effect by increasing the service life of equipment, various transport systems and individual structures, and also prevents the creation of emergency situations often accompanied by casualties and destruction of buildings and structures. 
The purpose of this work is to assess the effectiveness of protection by various variants of zinc-lamellar coatings under salt fog and biocorrosion conditions and identify the role of individual components, chemical and physical processes, as well as the contributions of the protective and barrier mechanisms to the protective ability of the deposited films.

This is extremely important since lamellar coatings and their high efficiency and other advantageous technological parameters of such coatings are not well known to the overwhelming majority of manufacturers and potential consumers in the Russian Federation, and the data obtained in this work will show the capabilities of lamellar coatings, expand their areas of application and predict directions for further research.

\section{Experimental}

Zinc-lamellar (scaly) coatings based on organic binders and titanium oxide glasses and their combinations were chosen as the objects of this study. During deposition from working suspensions onto a substrate, lamella flakes lie parallel to the surface, which allows the packing density of zinc at a given thickness to be increased significantly and the porosity of the coatings to be reduced.

Coatings were applied from suspensions on the surfaces of steel plates (St3 and St10) by aerography.

Samples with the following abbreviations were used for the corrosion studies:

1. $\mathbf{F}$ - a single-layer aluminum lamellar coating based on an epoxy binder with addition of 5\% Teflon and $20 \%$ aluminum lamellas.

2. Zn-AT-0 - a single-layer zinc-lamellar coating based on a titanium oxide binder containing $\sim 80 \%$ zinc embedded in the coating. No aluminum was present in the coating.

3. Zn-AT-50-50 - a single-layer zinc-lamellar coating based on a titanium oxide binder containing $~ 93 \%$ zinc embedded in the coating. A mixture of zinc lamellas (50\%) plus $50 \%$ zinc powder was used as the metal filler. No aluminum was present in the coating.

4. Zn-AT-7 - a single-layer zinc-lamellar coating based on a titanium oxide binder with a containing $\sim 84.2 \%$ zinc and $\sim 7 \%$ aluminum lamellas embedded in the coating.

5. Zn-ATF - a single-layer zinc-lamellar coating based on a titanium oxide binder with addition of fluoroplast $(\sim 5 \%)$, along with $\sim 80.7 \%$ zinc and $\sim 7 \%$ aluminum.

6. Zn-AT+F - a two-layer coating consisting of a lower sublayer (base) with the ZnAT composition and an upper (top) aluminum-lamellar layer based on an epoxy binder containing 5\% Teflon and 20\% aluminum.

7. Zn-ATF+F - a two-layer coating consisting of a lower layer with the Zn-ATF composition and an outer aluminum-lamellar layer based on an epoxy coating containing 5\% Teflon and $\sim 20 \%$ aluminum. 
In the case of coatings based on titanium oxide glasses and an organic binder, after applying the suspension to the surface, the were subjected to heat treatment in three stages: a) for 15 minutes at $50^{\circ} \mathrm{C}$; b) warming to $230^{\circ} \mathrm{C}$ at a rate of $12^{\circ} \mathrm{C} / \mathrm{min} ; \mathrm{c}$ ) exposure at $230^{\circ} \mathrm{C}$ for 15 minutes.

For bio-corrosion studies, museum-grade gram-negative strains of Pseudomonas aeruginosa spp. and gram-positive bacteria Bacillus subtillis were used as the test cultures, which, as shown in [1], produce up to 0.80 and $0.20 \mathrm{~mol} / \mathrm{L}_{2} \mathrm{O}_{2}$, respectively. The expediency of studying these microorganisms is caused by the fact that they are the most corrosive toward steel [1]. In addition, these microorganisms differ from each other in the structure of the cell wall and the processes of life, which is of interest in assessing the impact of these microorganisms on the coating.

Further in the text we will indicate these names as Ps. aeruginosa (-) and B. subtillis (+) to emphasize the gram-negative or gram-positive nature of these bacteria.

As a nutrient medium, meat-peptone agar was used: peptone $(10.5 \mathrm{~g} / \mathrm{L})$, meat hydrolyzate $(10.5 \mathrm{~g} / \mathrm{L})$, autolyzed yeast extract $(2 \mathrm{~g} / \mathrm{L})$, sodium chloride $(9 \mathrm{~g} / \mathrm{L})$, and agar$\operatorname{agar}(12 \mathrm{~g} / \mathrm{L})$.

Bacterial cultures were grown in Petri dishes with a solid nutrient medium in a dry-air thermostat at $37 \pm 2^{\circ} \mathrm{C}$ and an air humidity of $90 \%$. Solid nutrient medium was inoculated with aqueous suspension of 1-day bacterial cultures grown in test tubes on slant agar. Then, prepared metal samples were placed on the surface of the nutrient medium, which were then incubated in a thermostat at $37 \pm 2^{\circ} \mathrm{C}$ for 8 days, after which the nutrient medium was replaced with a new one. In these time intervals, a microscopic survey of the surface of the samples was carried out on a Keynce VHX-1000 digital optical microscope. Specimens not exposed to corrosion were used as control.

The choice of 8 days was dictated by the fact that the concentration of $\mathrm{H}_{2} \mathrm{O}_{2}$ in the exudate formed on the surface of the sample increases with time and reaches a maximum value after about 7 to 8 days of exposure, after which a decrease in its concentration is observed (Figure 1).

When conducting corrosion tests, two methods were used to prepare the samples:

a) a cross-section of the coating was made on the samples to the base metal and kept in a corrosive environment until traces of red corrosion of the base metal appeared near the cut. In this case, we recorded the time of protection of the base by the coating provided solely by the sacrificial metal embedded in the coating;

b) the samples with intact coatings were kept in a microbiological environment and salt spray. The presence of foci of red corrosion of the steel substrate, blisters, etc. on the surface of the coatings was determined, visually or with a microscope at the intervals indicated above. In this case, the protective ability of coatings is due to the sacrificial and barrier protection mechanisms. 


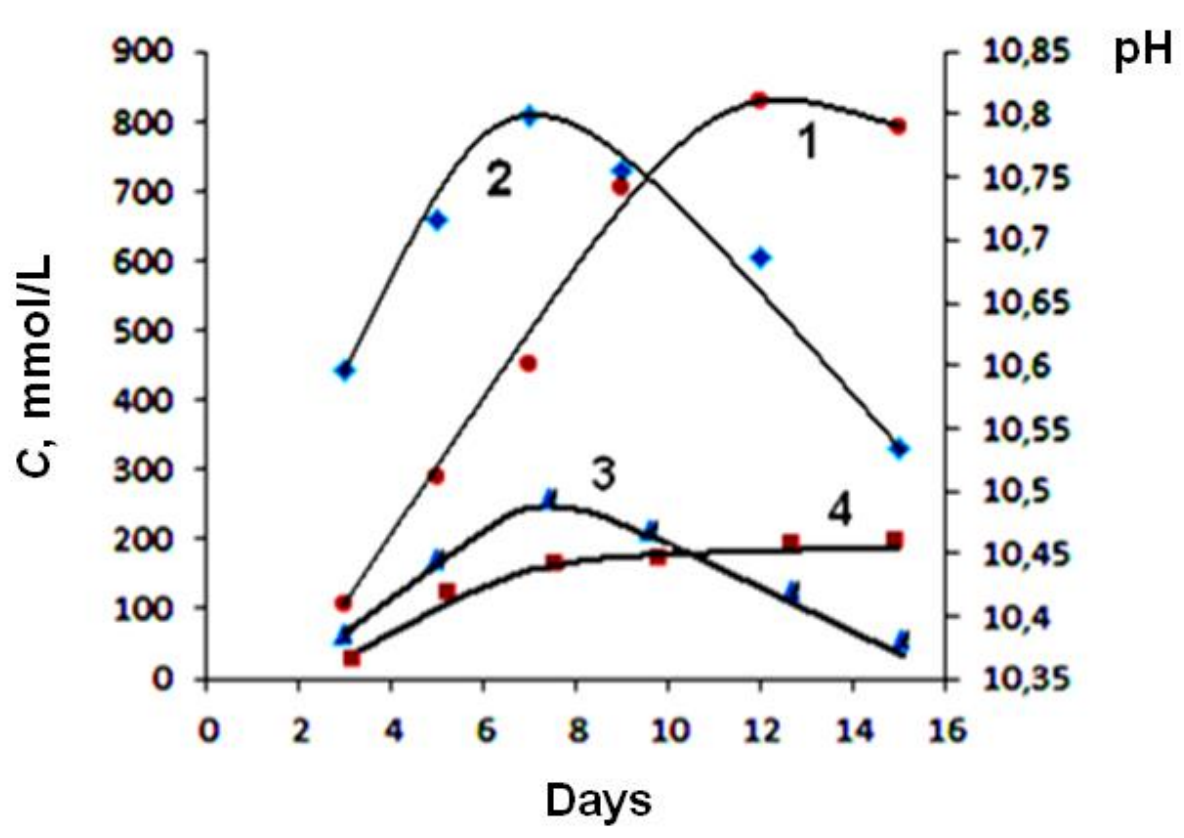

Figure 1. Dependence of $\mathrm{pH}$ (curves 1 and 4) and $\mathrm{H}_{2} \mathrm{O}_{2}$ concentration (curves 2 and 3 ) on time for bacteria Ps. aeruginosa (-) (curves 1 and 2) and B. subtillis (+) (curves 3 and 4).

To assess the contribution of the sacrificial protection mechanism, it is necessary to find the ratio of the time until the appearance of red corrosion on the notched coatings (sacrificial protection) to the time of appearance of corrosion on undisturbed samples (sacrificial and barrier protection): $\gamma_{\mathrm{pr}}=\tau_{\mathrm{dis}} / \tau_{\text {undis. }}$. To assess the barrier mechanism, respectively, the following ratio was used: $\left(\gamma_{\mathrm{bar}}=1-\gamma_{\mathrm{pr}}\right)$.

The thickness of the coatings was controlled with a "Constant K5" thickness gauge according to GOST R 51694-2000 [2].

To determine the amount of electrochemically active zinc and the coefficient of its utilization in the coatings, the potentiodynamic method was used. Anodic potentiodynamic curves were recorded at potential sweep rates of 0.05 and $0.5 \mathrm{mV} / \mathrm{s}$. The measurements were carried out in a pressure cell of an electrochemical cell with free access of air in a $5 \% \mathrm{NaCl}$ solution, by the method described in detail in [3]. A saturated silver chloride electrode was used as the reference electrode.

A more detailed description of surface preparation and production of working suspensions, methods for deposition of coatings and control of their parameters is provided in $[3,4]$.

\section{Results and discussion}

Using the $\mathrm{Zn}-\mathrm{AT}+\mathrm{F}$ coating applied on steel as an example, Figures 2 and 3 show typical micrographs of the original surface (Figures 2a, 3a) and after 5800 hours of incubation with B. subtillis (+) (Figure 2b) and after 4300 hours with Ps. aeruginosa (-) (Figure 3b) when visible signs of corrosion exist. 


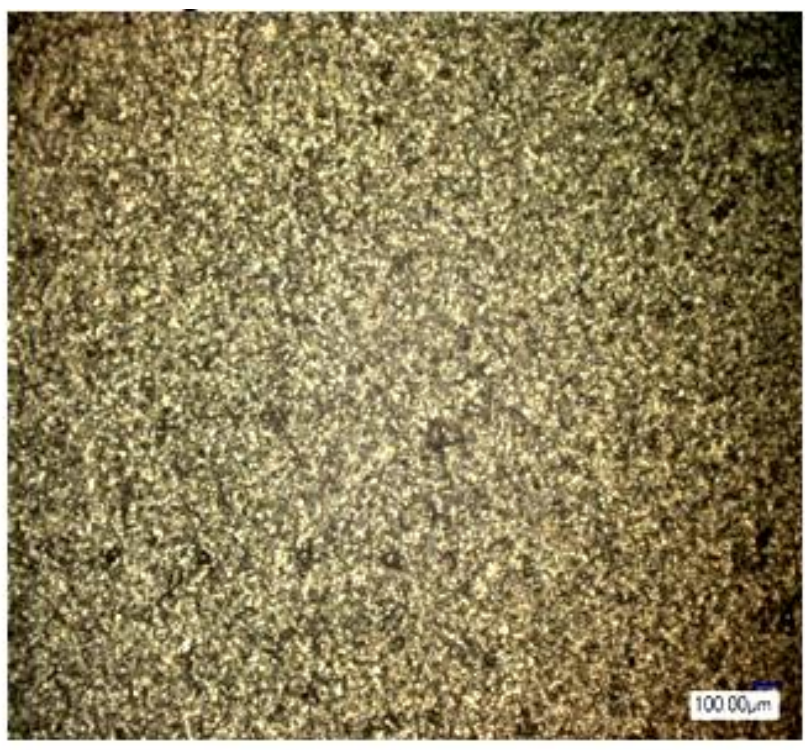

$a$

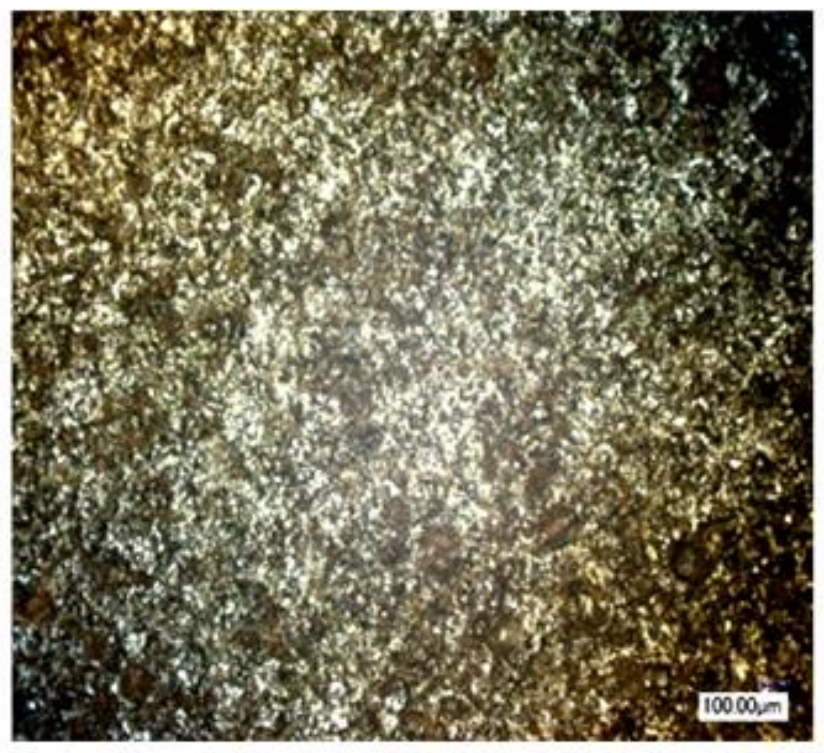

$b$

Figure 2. Micrographs of the initial surface of $\mathrm{Zn}-\mathrm{AT}+\mathrm{F}$ coatings $(a)$ and after 5800 hours of exposure with B. subtillis (+) (b); x100.

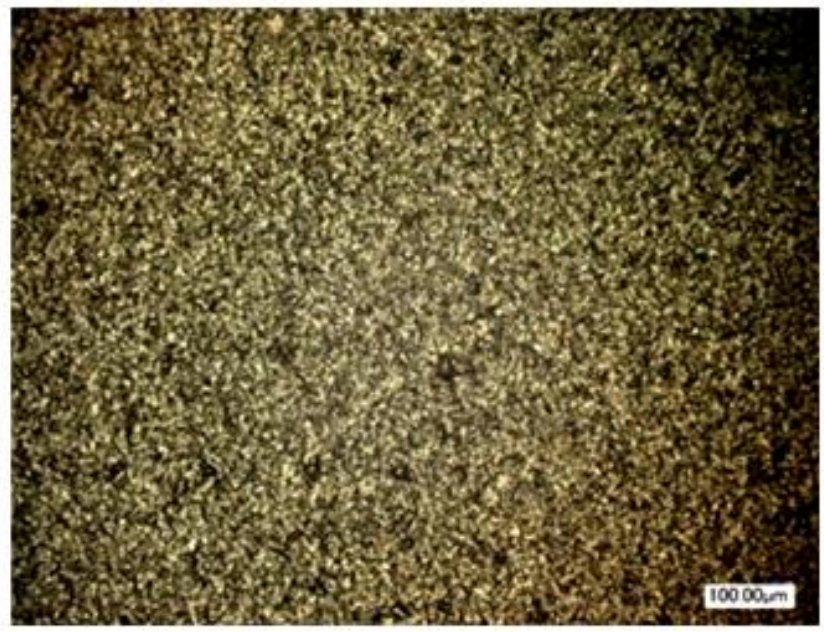

$a$

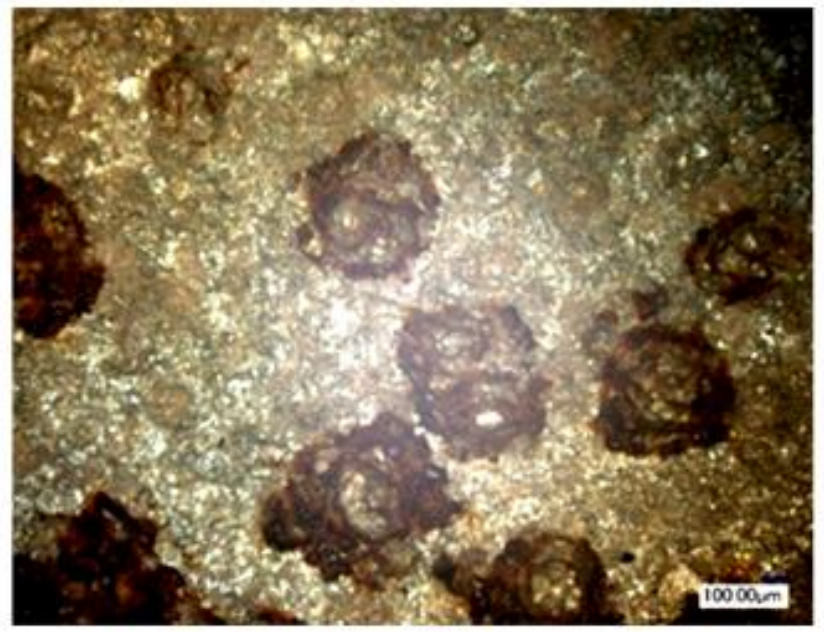

$b$

Figure 3. Micrographs of the initial surface of Zn-AT + F coatings $(a)$ and after 4300 hours of incubation with Ps. aeruginosa (-) (b); x100.

The experimental data on some parameters of the studied coatings are summarized in Tables 1 and 2. The following parameters were used: $Q_{\text {ech }}, \mathrm{C} / \mathrm{cm}^{2}$ is the amount of electrochemically active zinc in the coating obtained on the basis of potentiodynamic measurements; $\tau_{\mathrm{n}}$ is the time until red corrosion appears on undisturbed surfaces of the coatings; $\tau_{\mathrm{r}}$ is time before the appearance of red corrosion on cross-cut coatings; $K_{\text {us }}=Q_{\Sigma} / Q_{\text {ech }}$ is the coefficient of utilization of zinc embedded in the coating for the time 
before the appearance of red corrosion on undisturbed samples; $Q_{\Sigma}$ is the total amount of zinc incorporated in the coating in the form of zinc lamellae; $\gamma_{\mathrm{pr}}=\tau_{\mathrm{dis}} / \tau_{\text {undis }}$ is the contribution of the sacrificial protection; and $\gamma_{\mathrm{bar}}=1-\gamma_{\mathrm{pr}}$ is the contribution of the barrier protection mechanism.

For comparison of the corrosivity of the bacterial environment and the above parameters, Table 3 presents similar data for coatings tested in the salt fog chamber according to GOST 9.401-91 [5].

Table 1. Coating parameters after exposure to B. subtillis (+) and Ps. aeruginosa (-).

\begin{tabular}{|c|c|c|c|c|c|c|c|c|}
\hline \multirow[b]{2}{*}{ Coating } & \multirow{2}{*}{$\begin{array}{l}\text { The number of } \\
\text { layers in the } \\
\text { coating/layer } \\
\text { thickness, } \\
\mu \mathrm{m}\end{array}$} & \multicolumn{2}{|c|}{$\begin{array}{c}\text { Time to corrosion, } \\
\text { hours }\end{array}$} & \multirow{2}{*}{$\begin{array}{c}Q_{\mathrm{ech}} \\
\mathrm{C} / \mathrm{cm}^{2}\end{array}$} & \multirow{2}{*}{\multicolumn{2}{|c|}{$\begin{array}{c}K_{\mathrm{us}} \text { of zinc, } \\
\%\end{array}$}} & \multirow[b]{2}{*}{$\underset{\%}{\gamma p}$} & \multirow[b]{2}{*}{$\begin{array}{c}\gamma_{\text {bar, }} \\
\%\end{array}$} \\
\hline & & $\mathbf{A}$ & B & & & & & \\
\hline $\mathrm{F}$ & $1 / 15$ & 240 & 120 & 0 & \multicolumn{2}{|c|}{0} & - & - \\
\hline Zn-AT-7 & $1 / 15$ & 720 & 370 & 7.47 & \multicolumn{2}{|c|}{90} & $30-32$ & $68-70$ \\
\hline $\mathrm{Zn}-\mathrm{ATF}$ & $1 / 15$ & 700 & 340 & 4.95 & \multicolumn{2}{|c|}{74} & $22-24$ & $76-78$ \\
\hline $\mathrm{Zn}-\mathrm{AT}+\mathrm{F}$ & $2 /(15+5)$ & 4800 & 2600 & 6.68 & \multicolumn{2}{|c|}{83} & $13-15$ & $85-87$ \\
\hline $\mathrm{Zn}-\mathrm{ATF}+\mathrm{F}$ & $2 /(15+5)$ & 4100 & 1800 & 2.90 & \multicolumn{2}{|c|}{58} & $13-15$ & $85-87$ \\
\hline \multicolumn{9}{|c|}{$\begin{array}{l}\mathrm{A}-\text { B. subtillis }(+) \\
\mathrm{B}-P . \operatorname{aeruginosa}(-)\end{array}$} \\
\hline Coating & $\begin{array}{l}\text { The number of } \\
\text { layers in the } \\
\text { coating/layer } \\
\text { thickness, } \mu \mathrm{m}\end{array}$ & & & $\begin{array}{c}Q_{\mathrm{ech}} \\
\mathrm{C} / \mathrm{cm}^{2}\end{array}$ & $\begin{array}{c}K_{\mathrm{us}} \text { of zinc, } \\
\%\end{array}$ & $\begin{array}{c}\gamma_{\mathrm{pr}}, \\
\%\end{array}$ & & $\begin{array}{c}\gamma_{\text {bar, }} \\
\%\end{array}$ \\
\hline $\mathrm{F}$ & $\mathrm{h}$ & & & 0 & 0 & - & & - \\
\hline Zn-AT 50:50 & $1 / 15$ & & & 10.07 & 100 & $89-92$ & & $8-11$ \\
\hline Zn-AT-0 & $1 / 15$ & & & 8.74 & 100 & $77-79$ & & $21-23$ \\
\hline Zn-AT-7 & $1 / 15$ & & & 7.47 & 90 & $29-31$ & & $59-71$ \\
\hline $\mathrm{Zn}-\mathrm{ATF}$ & $1 / 15$ & & & 4.95 & 74 & $22-24$ & & $76-78$ \\
\hline $\mathrm{Zn}-\mathrm{AT}+\mathrm{F}$ & $2 /(15+5)$ & & & 6.68 & 83 & $14-16$ & & $34-86$ \\
\hline $\mathrm{Zn}-\mathrm{ATF}+\mathrm{F}$ & $2 /(15+5)$ & & & 2.90 & 58 & $12-16$ & & $34-88$ \\
\hline
\end{tabular}


From Tables 1 and 2 we can draw the following conclusions:

1) Ps. aeruginosa (-) bacteria producing hydrogen peroxide as a metabolite in much larger quantities $(\sim 0.8 \mathrm{~mol} / \mathrm{L})$ than gram-positive $B$. subtillis $(0.2 \mathrm{~mol} / \mathrm{L})$ at almost the same $\mathrm{pH} 10.5-10.8$ (Figure 1), both for single-layer and two-layer coatings, reduce the time until the appearance of red corrosion of coatings two-fold on average;

2 ) With an increase in the amount of electrochemically active zinc in coatings, the protective ability of coatings increases by about the same amount;

3) In coatings that do not contain added aluminum, for example, Zn-AT-0 in which the quantity of active zinc $Q_{\text {ech }}=8.74 \mathrm{C} / \mathrm{cm}^{2}$ and Zn-AT 50:50 $\left(Q_{\text {ech }}=10.07 \mathrm{C} / \mathrm{cm}^{2}\right)($ Table 2) with $100 \%$ utilization of zinc embedded in the coating, the main contribution to the protective ability of the coatings is made by the sacrificial mechanism: 79 and $91 \%$, respectively.

The higher values of Zn-AT 50-50 coating durability compared to Zn-AT-0 coating are due to the fact that the use of mixtures of zinc lamella and zinc powder leads to an increase in the filling density of zinc coating until the lamella: powder ratio of 50:50 is reached. With a further increase in the powder amount, the packing density decreases, which leads to an increase in the porosity of the coatings and to unproductive consumption of the protector due to elevated corrosion of zinc in the coating.

4) When aluminum is included in the coating in amounts of [Al] $>3 \%$, both in singlelayer (for example, Zn-AT-7) and two-layer coatings, the protective action mechanism changes dramatically: the barrier protection mechanism $\left(\gamma_{\mathrm{bar}} \approx 70 \%\right)$ prevails. The reason for this effect is probably that the specific surface area of zinc lamellas is $\sim 1 \mathrm{~m}^{2} / \mathrm{g}$ and that of aluminum is eight times larger, $\sim 8 \mathrm{~m}^{2} / \mathrm{g}$. Large aluminum lamellae cover most of the zinc particles and overlap the gaps between the zinc lamellas. This effect reduces the porosity of the coatings and access of the electrolyte to the protector and the steel base, thus leading to a sharp increase in the barrier properties of the coatings.

It should be noted that the contribution of the barrier mechanism in two-layer coatings is $8-16 \%$ greater than in single-layer coatings, which is quite natural, as the coating thickness increases (by $5 \mu \mathrm{m}$ ), and also due to a misalignment of the pore networks in the first and second layers, as a result of which the boundary on these layers plays the role of a "locking" layer.

The correctness of this reasoning is confirmed by the data on the replacement of aluminum in the second layer $(\delta=5 \mu \mathrm{m})$ for mica lamellae having the same geometrical dimensions as aluminum, as well as by the data of potentiodynamic measurements (Figure 4). In both cases, the barrier properties of coatings increase dramatically. 


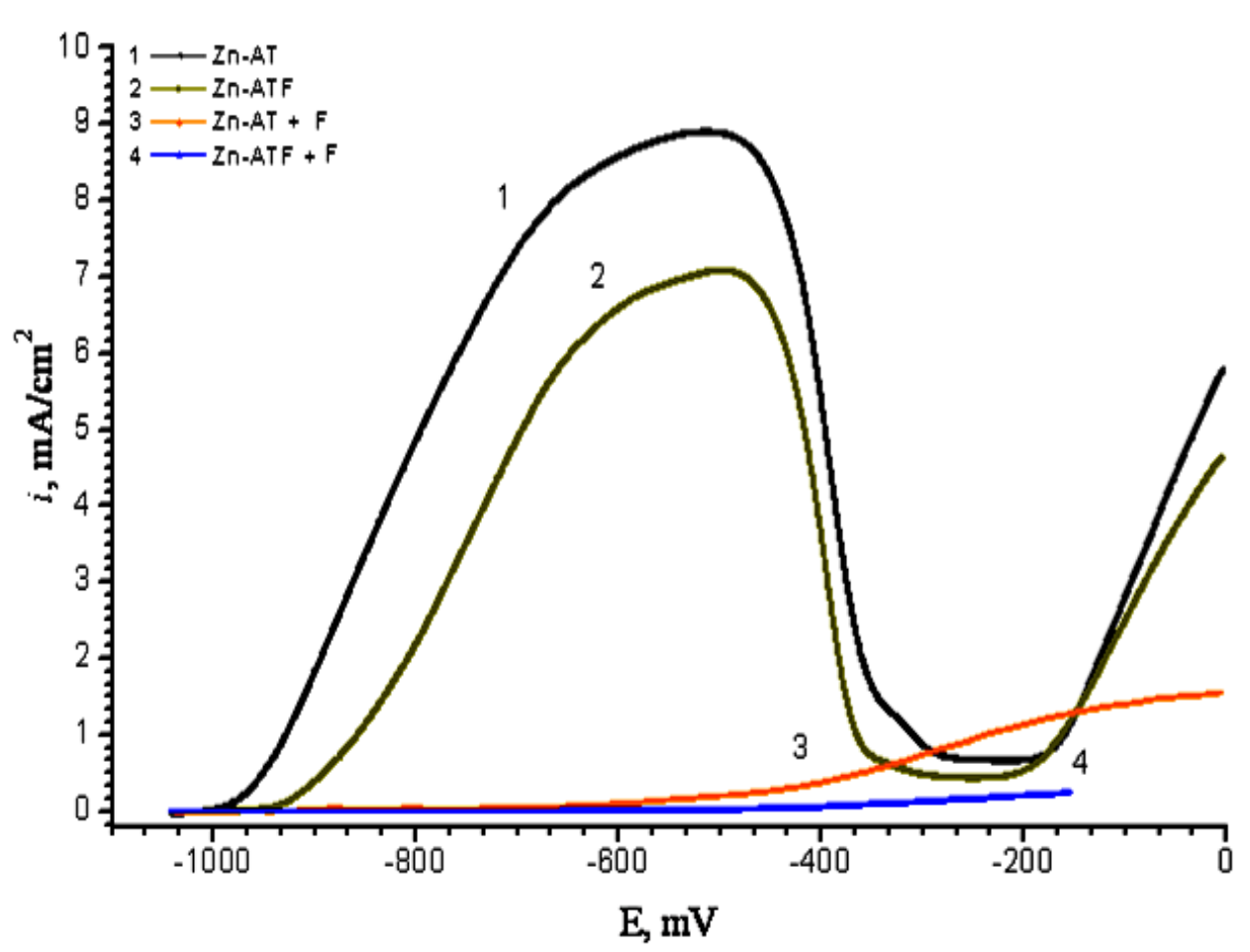

Figure 4. Anodic potentiodynamic curves of coatings with the compositions: Zn-AT (curve 1); Zn-ATF (curve 2); Zn-AT+F (curve 3) and Zn-ATF+F; $V=0.5 \mathrm{mV} / \mathrm{s} ; 5 \% \mathrm{NaCl}$.

It follows from Figure 4 that in single-layer Zn-AT and Zn-ATF coatings the oxidation of zinc is not hindered (curves 1 and 2) and the entire zinc is extracted during the passage of the first current maximum at $V=0.5 \mathrm{mV} / \mathrm{s}$.

Some decrease in the amount of reactive zinc on switching to Zn-AT compared to $\mathrm{Zn}-\mathrm{ATF}$ is due to the fact that in Zn-ATF, the amount of embedded zinc is $3.5 \%$ smaller, and the surface fraction of zinc lamellae blocked by the binder and Teflon is likely to increase by about the same amount.

On switching to a two-layer coatings, the zinc oxidation process slows down sharply (see Figure 4, curves 3 and 4). The reactive zinc can be completely removed by reducing the potential sweep rate by an order of magnitude (down to $0.05 \mathrm{mV} / \mathrm{s}$ ). In this case, the second current maximum does not show the presence of electrochemically active zinc remaining after the first maximum (Figure 5).

5) Due to the lack of zinc protector, the F coatings containing epoxy, Teflon and aluminum lamellas have a three-fold smaller protection performance when exposed to $B$. subtillis (+) and Ps. aeruginosa (-) bacteria than the coatings containing zinc (Tables 1 and 2).

6) $\mathrm{F}$ coatings in salt fog last for a 5-10 times shorter period ( 24 hours) than in the environment containing B. subtillis (+) and Ps. aeruginosa (-) bacteria, namely 120 and 240 hours, respectively, due to the following: 


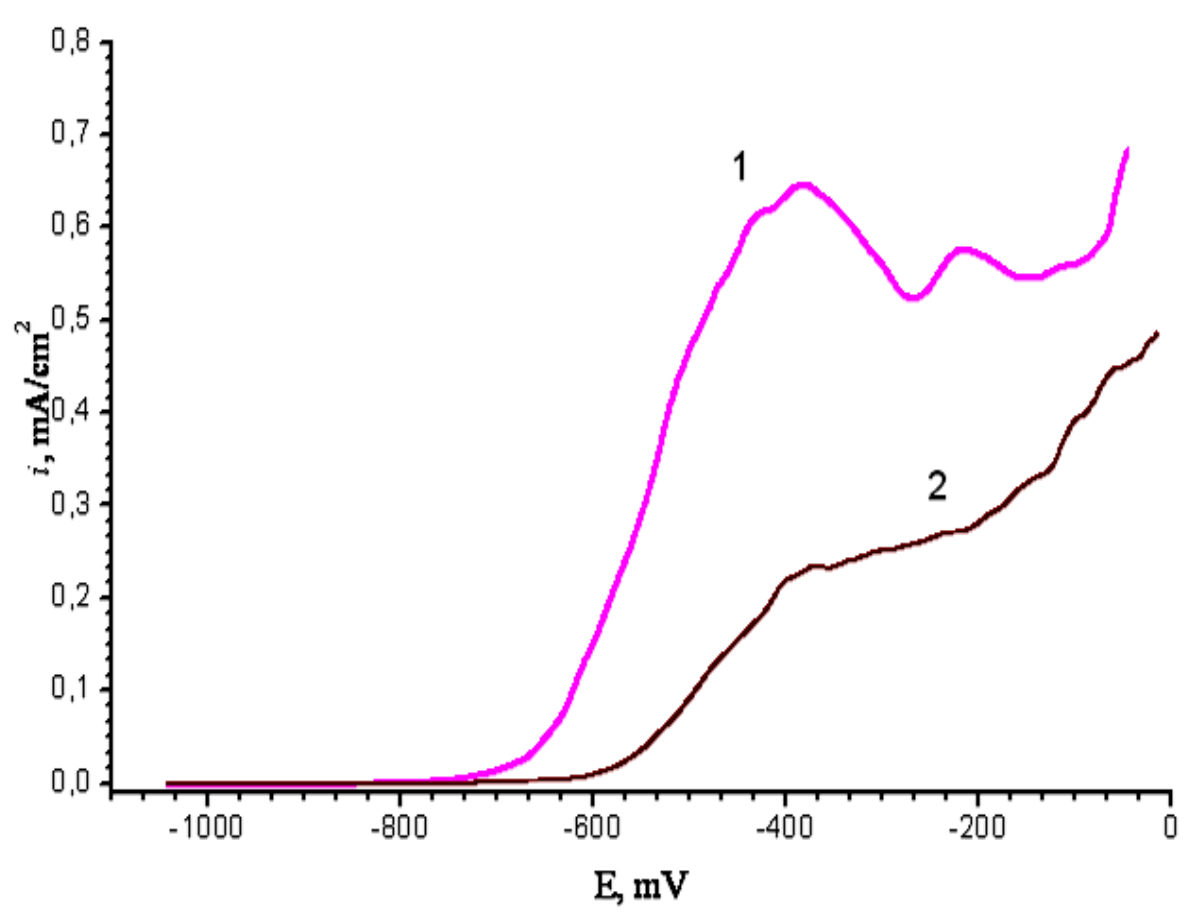

Figure 5. Anodic potentiodynamic curves of $\mathrm{Zn}-\mathrm{AT}+\mathrm{F}$ (curve 1) and $\mathrm{Zn}-\mathrm{ATF}+\mathrm{F}$ (curve 2) of coatings at $V=0.05 \mathrm{mV} / \mathrm{s}: \delta=20 \mu \mathrm{m} ; 5 \% \mathrm{NaCl}$ electrolyte.

a) the amount of hydrogen peroxide produced in the microbiological environment during the first day is minor (Figure 1), while in the salt fog chamber the amount of dissolved oxygen under the conditions of intense salt fog mixing is always constant and is significantly higher than in a stagnant liquid (the concentration of dissolved oxygen in stagnant water is $\sim 5-7 \mathrm{~cm}^{3} \mathrm{O}_{2} / \mathrm{L}$ according to [6]);

b) in the salt fog chamber, the surface of metal samples is intensely washed with a salt solution saturated with oxygen, which practically eliminates the diffusion component of the corrosion process, while in biocorrosion, the contribution of the diffusion component of the process is much greater, since the bacterial culture exudate does not move during corrosion tests.

7) The investigated microbiological environment is more corrosive than the salt fog. This is especially noticeable for single-layer coatings. For example, the resistance of Zn-AT coatings in a microbiological environment is within 290-720 hours, whereas it is $\sim 1500$ hours in the salt fog. This is due to the fact that in the microbiological environment $\mathrm{H}_{2} \mathrm{O}_{2}$ acts as an oxidizing agent whose potential at $\mathrm{pH} 10.5$ equals $E_{\mathrm{OH}^{-} / \mathrm{H}_{2} \mathrm{O}_{2}}=1.05 \mathrm{~V}$ $\left(E_{\mathrm{OH}^{-} / \mathrm{H}_{2} \mathrm{O}_{2}}=1.362-0.0295 \mathrm{pH}[7]\right)$.

The corrosion of iron and zinc in salt fog occurs by the oxygen depolarization mechanism. In this case, the potential of oxygen as the oxidizing agent at $\mathrm{pH} 10.5$ is $E_{\mathrm{O}_{2} / \mathrm{H}_{2} \mathrm{O}}$ $=0.607 \mathrm{~V}\left(E_{\mathrm{O}_{2} / \mathrm{H}_{2} \mathrm{O}}=1.228-0.0591 \mathrm{pH}\right)$. Such a large difference in the potentials of the 
oxidizing agents makes the microbiological medium being studied more corrosive than the salt fog.

8) In two-layer coatings where a thin outer layer that does not contain zinc is added to the base layer, the time of the protective action increases several times, both in the microbiological environment and in the salt fog. This occurs for the following reasons: a) the misalignment of the pore network at the boundary of these two layers; b) a large amount of aluminum embedded in the outer layer $(\sim 20 \%)$, which increases the barrier protection due to the high covering ability of aluminum lamellae and the ability of aluminum to regenerate zinc from its corrosion products.

Chloride ions, which are aluminum depassivators, are present in the media tested by us, which makes it possible for aluminum to displace zinc from its corrosion products in aqueous solutions. In this case, the total process of zinc regeneration in the Al-Zn galvanic couple in an alkaline medium can be described by the following reactions:
$\mathrm{Al}$ anode (-):
$2 \mathrm{Al}+6 \mathrm{OH}^{-}-6 \mathrm{e}=2 \mathrm{Al}(\mathrm{OH})_{3}$
$\mathrm{Zn}$ and Fe cathode (+):

$$
3 \mathrm{Zn}(\mathrm{OH})_{2}+6 \mathrm{e}=3 \mathrm{Zn}+6 \mathrm{OH}^{-}
$$
In total:

$$
2 \mathrm{Al}+3 \mathrm{Zn}(\mathrm{OH})_{2}=2 \mathrm{Al}(\mathrm{OH})_{3}+3 \mathrm{Zn}
$$

The Gibbs energy of the reaction (eq. 3) is negative, $\Delta G^{0}=-698 \mathrm{~kJ} / \mathrm{mol}$, and the solubility product of zinc hydroxide is $\mathrm{SP}=1.2 \cdot 10^{-17}$ is fifteen orders of magnitude greater than that of $\mathrm{Al}(\mathrm{OH})_{3}\left(\mathrm{SP}=1.0 \cdot 10^{-32}\right)$, which shifts the equilibrium (eq. 3) in favor of the direct reaction.

The regeneration process (eq. 3) increases the utilization rate of zinc in both singlelayer (Zn-AT-3, Zn-AT-7) and two-layer (Zn-ATF+F and Zn-AT+F) coatings, which leads to an increase in their protective action.

The assumption about the regeneration of zinc with aluminum is confirmed by experimental data [8], according to which in neutral chloride solutions with $\left[\mathrm{Cl}^{-}\right] \leq 2 \cdot 10^{-1} \mathrm{M}$ aluminum precipitates zinc in contact manner from zinc-containing mine waters with an efficiency of about $60 \%$.

Regeneration of zinc by aluminum by the reaction (eq. 3) results in a 1.5-fold decrease in the volume of well-permeable $\mathrm{Zn}(\mathrm{OH})_{2}$ compared to the newly formed $\mathrm{Al}(\mathrm{OH})_{3}$. This reduces the porosity of coatings and favors an increase in their protective action.

The decrease in the amount of white zinc corrosion products is confirmed by images of the surface of zinc-lamellar coatings with 10\% aluminum and without additives (Figure 6). It can be seen from the SE-images that the amount of products of white corrosion of zinc decreases markedly in the presence of aluminum.

It should be noted that during the corrosion tests, zinc in a bacterial environment is consumed in two processes: a) dissolution due to sacrificial protection during the operation of the galvanic couple ${ }^{(-)} \mathrm{Zn} / \mathrm{NaCl}, \mathrm{H}_{2} \mathrm{O} / \mathrm{Fe}^{(+)}$and $b$ ) due to corrosion by the oxygen depolarization mechanism, as well as in the direct reaction of zinc and hydrogen peroxide:

$$
\mathrm{Zn}+\mathrm{H}_{2} \mathrm{O}_{2}=\mathrm{Zn}(\mathrm{OH})_{2}
$$




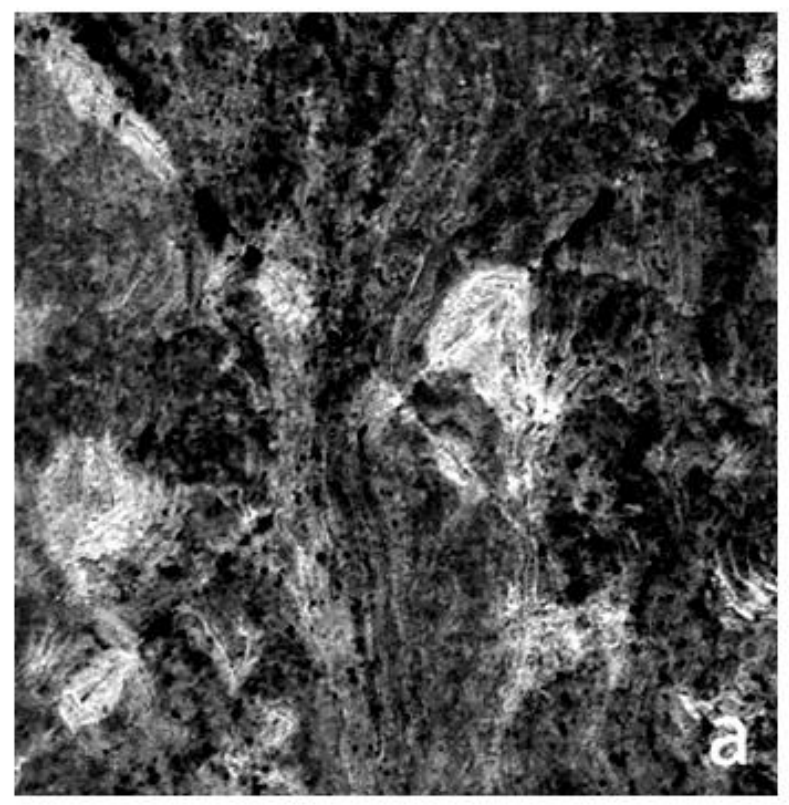

$a$

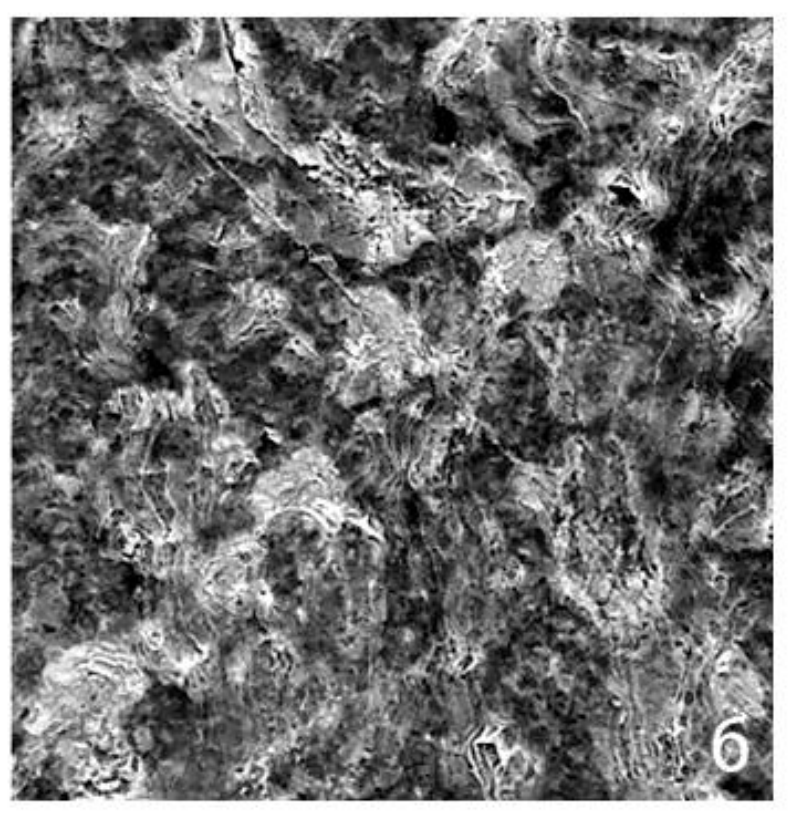

$b$

Figure 6. Notched coatings after 144 hours exposure in a salt fog chamber containing $26.5 \%$ epoxy resin with different fillings: $a-\mathrm{Zn}+10 \%$ Al-lamella; $b-\mathrm{Zn}$-lamellae; $\delta=15 \mu \mathrm{m}$.

To increase the protective ability of coatings and provide a more efficient zinc consumption, it is necessary to minimize the corrosion of zinc in the coating. This is achieved by introducing aluminum lamellae, which have a large covering ability, into the coatings for reducing the porosity of coatings and hindering the access of the electrolyte to the surface of zinc, and regenerating zinc with aluminum.

\section{Conclusions}

Thus, incorporation of aluminum in quantities of $\geq 7$ mass $\%$ into zinc-containing coatings result in a sharp increase in the protective action of coatings due to the following effects:

a) aluminum is a regenerating agent with respect to zinc ions, resulting in the reproduction of metallic zinc from its corrosion products for a long time;

b) due to the large covering ability of aluminum lamellae and a decrease in the amount of loose corrosion products in the presence of aluminum, the transportation of oxidizing agents (hydrogen peroxide and oxygen) and the electrolyte to the surface of zinc and the steel base is hindered.

\section{Acknowledgments}

This study was financially supported by RFBR under Research project No.18-33-01003/18. 


\section{References}

1. A.A. Kalinina, Simulation of the conditions of oxygen biotransformation by organotrophy bacteria in hydrogen peroxide which stimulates zinc corrosion, $I z v$. VUZov, Prikl. Khim. Biotekhnol. (News of universities. Applied chemistry and biotechnology), 2017, 7, 80-88 (in Russian). doi: 10.21285/2227-2925-2017-7-2-80-88

2. GOST R 51694-2000 "Paintwork materials. Determination of coating thickness" (in Russian).

3. V.I. Chumakov, V.I. Naumov, I.V. Chumakov and S.L. Katraev, Antikorrozionnye svoistva tsinkovykh i tsink-alyuminievykh lamel'nykh pokrytii na stali (Anticorrosion properties of $\mathrm{Zn}$ and $\mathrm{Zn}-\mathrm{Al}$ lamellar coatings on steel), Gal'vanotekh. Obrab. Poverkhn. (Electroplating and surface treatment), 2012, 20, 17-22 (in Russian).

4. R.V. Galkin, V.I. Chumakov and V.I. Naumov, Termootverzhdaemoe tsink-lamel'noe pokrytie na osnove epoksidnoi smoly (Thermo-hardenedzinc-lamel coating on the basis on epoxy-resin), Gal'vanotekh. Obrab. Poverkhn. (Electroplating and surface treatment), 2018, 26, 10-17 (in Russian).

5. GOST 9.401-91. Paint coatings. General requirements and methods for accelerated testing for resistance to climatic factors, Moscow, 2007 (in Russian).

6. A.N. Petin, M.G. Lebedeva and O.V. Krymskaya, Analiz $i$ otsenka kachestva poverkhnostnykh vod (Analysis and assessment of the quality of surface water), 2006, Belgorod: Publ. at BelSU, p. 252 (in Russian).

7. Chemist's Reference, 1964, Moscow, Khimiya, p. 1008 (in Russian).

8. N.N. Orekhova and N.A. Chalkova, Technological solutions for the extraction of zinc from drainage waters, Gornyi informatsionno-analiticheskii byulleten' (Mining information and analytical bulletin), 2012, 7, 290-294 (in Russian). 